\title{
Numerical Analysis on the Performance of Dual Rotor Wind Turbine
}

\author{
${ }^{1}$ Hazem Ali Abdel Karim ${ }^{*}{ }^{2}$ Ahmed Reda El-Baz, ${ }^{3}$ Nabil Abdel Aziz Mahmoud, \\ ${ }^{4}$ Ashraf Mostafa Hamed \\ ${ }^{1,3,4}$ Mechanical Power Engineering Department, Ain shams University, Cairo, Egypt. \\ ${ }^{2}$ Mechanical Power Engineering Department, British University in Egypt, Cairo, Egypt.
}

\begin{abstract}
This This study investigates the aerodynamic performance of wind turbines aiming to maximize the power extracted from the wind. The study is focusing on the effect of introducing a second rotor to the main rotor of the wind turbine in what is called a dual rotor wind turbine (DRWT). The numerical study took place on the performance of small-scale model of wind turbine of 0.9 m diameter using S826 airfoil.

Both the Co-rotating and Counter rotating configurations were investigated at different tip speed ratios (TSR) and compared with the performance of the single rotor wind turbine (SRWT). Many parameters were studied for dual rotor turbines. These include the spacing between the two rotors, the pitch angle of the rear rotor and the rotational speed of ratio rear to front rotor. Three-dimensional simulations performed and employed using CFD simulations with Multi Reference Frame (MRF) technique.

The Co Rotating Wind Turbine (CWT) and Counter Rotating Wind Turbine (CRWT) found to have better performance compared to that of the SRWT with an increase ranging from 12 to $14 \%$ in peak power coefficient. Moreover, the effect of changing the pitch angle of the rear rotor on the overall performance found to be of a negligible effect between angles $0^{0}$ until $2^{0}$ degrees tilting toward the front rotor. On the other hand, the ratio of rotational speed of the rear rotor to the front rotor found to cause a further increase in the peak performance of the CWT and CRWT ranging from 3 to 5\%.
\end{abstract}

Keywords: Dual rotor wind turbines-Counter rotating wind turbines-Co rotating wind turbinesComputational fluid dynamics- Power coefficient.

\section{Abbreviations}

Computational Fluid Dynamics

CFD

Coefficient of performance

$\mathrm{Cp}$

Counter rotating wind turbine

CRWT

Co rotating wind turbine

CWT

Dual rotor wind turbine

DRWT

Multi reference frame

MRF

Single rotor wind turbine

SRWT

Shear stress theory

SST

Tip speed ratio

TSR

\section{Introduction}

Wind power is a clean source of renewable energy and its conversion to usable energy is vital in order to reduce fossil fuel dependency. Wind energy can provide an eco-friendly solution for energy production. Wind energy is estimated to be a source of around 10 million MW of energy that are present on earth and ready to be used (Council, 2015). Wind turbines focuses on converting the kinetic energy in the upcoming 
wind and convert it to mechanical energy and then into electrical power. Recently, there has been a numerous attempts to get the best use of the wind energy.

The researchers are focusing on getting use from the power in the upcoming wind. That influenced the researches to be directed towards the new idea of DRWT. The system simply is composed of two rotors installed on the same tower. The two rotors composed of upstream and downstream rotors, the downstream rotor can harvest the unused energy in the wake of the upwind rotor. The new idea introduced theoretically proven to capture more energy than the 59\% proven known as Betz limit (Newman , Multiple Actuator Disc Theory for wind turbines, 1986).

The direction of the downstream rotor relative to the upstream rotor is referring to the dual rotor naming. The Two configurations are the CWT in which the two rotors rotates in same direction. The other configuration in which the rear rotor is opposing the upstream rotor rotation direction known to be the CRWT.

\section{Literature Review}

The design optimization of the wind turbine has passed through different phases and handled in different previous researches. (Hsiao, Bai, \& Chong, 2013) done an experimental study on Horizontal Axis Wind Turbine (HAWT) of $0.72 \mathrm{~m}$ diameter. The Blade having NACA 4418 airfoil profile was studied using BEM theory and CFD simulation. The paper has used the MRF technique in its CFD simulation and the K-w Shear Stress Transport (SST) turbulence model. The study showed the variation in coefficient of performance at different TSR. The three designs proposed are optimal twist and tapered blade (OPT), untapered and optimum twist (UOT) and untapered and untwisted (UUT). The study concluded that the best performance resulted is in case of the OPT design especially at the range of TSR between 4.5 and 7 . In addition, the paper showed that there is a high degree of agreement between the results from the experimental work and the CFD simulation results. In addition, (Abdelrahman, Abdellatif, Moawed, Eliwa, \& Misak, 2015) has done a similar study on $0.65 \mathrm{~m}$ blade radius. The paper results confirm with (Hsiao, Bai, \& Chong, 2013) showing that the best coefficient of performance was found for the OPT design. (Krogstad $\&$ Lund, An experimental and numerical study of the performance of a model turbine, 2012) done a study in national renewable energy laboratory (NREL) in Colorado on $0.9 \mathrm{~m}$ diameter SRWT of S826 airfoil. Also further analysis using BEM theory and computational study using CFD took place. The turbulence model of K-w SST was used. MRF technique was used in the CFD simulation agreeing with (Hsiao, Bai, \& Chong, 2013) in the advantage of the periodic planes and thus reducing the computational domain size. The results obtained are of high conformity with the experimental results.

Dual rotor wind turbines (DRWT) is studied starting from 1983, when (Newman, Actuator Disc Theory for Vertical Axis Wind Turbines, 1983) has proven using a actuator disc theory in One dimensional theoretical study, that the maximum power coefficient can exceed the 59\% which is proven theoretically by Betz in case if a second rotor of same diameter is introduced downstream of the first one. The paper showed that the theoretical power coefficient has increased from 59\% to $64 \%$ at high TSR, in case of neglecting the drag effect and the rotation in the wake.

Placing two rotors in wind farms and analyzing the separating distance between them was studied in 2011 by (Krogstad \& Adaramola, Experimental investigation of wake effects on wind turbine performance, 2011). They investigated experimentally in wind tunnel the effect of the spacing between two turbines on the performance of the rear rotor. Stating that changing the distance separating the two rotors from 3D to 9D has its reflection on the power loss of $49 \%$ at spacing of 3D and goes down to $29 \%$ at spacing of 9D due to the recovery of power gradually with increasing the separating distance. Also they referred to an expected dramatic decrease in the rear rotor performance once the front rotor is operated at its peak TSR as a SRWT which agrees with results presented by. (Lee, Son, \& Lee, Velocity ingerference in the rear rotor of a counter rotating wind turbine, 2013). In 2014, (YUAN, Tian, Ozbay, \& Hu, 2014) conducted a study regarding the direction of rotation recommended for the rear rotor. It stats that better performance in wind farms was found when the rear rotor is rotating in counter direction from the front one. According to the study, the CRWT extracts $17 \%$ more power than the CWT. Increasing the distance separating the two rotors to 6.5D, the rotation direction of the rear rotor becomes with no effect. 
In 2013, (Lee, Son, \& Lee, Velocity ingerference in the rear rotor of a counter rotating wind turbine, 2013) has done a numerical study on CRWT of $4.5 \mathrm{~m}$ diameter using free wake vortex lattice method. The study referred to the decay in the upwind velocity of the upcoming stream when passing over the front rotor, resulting in the wind stream energy arriving at the second rotor is much less than that at the front rotor. In the study, the axial separating distance between the two rotors is half the rotor radius. The study revealed that the power coefficient increase in case of the CRWT could reach up to $12 \%$. According to the study, the distance separating the two rotors has no significant effect on the performance. On the other hand, in study held by (Shen, Zakkam, Sorensen, \& Appa, 2007), they referred to a possible decrease in the Cp at close orientation between front and rear rotors due to thrust coefficient fluctuations.

(Lee, Kim, Son, \& Lee, 2012) also investigated the effect of the pitch angle and the rotating speeds on the performance of CRWT. The paper recommended the reduction of the rear rotor rotating speed to 0.7 of the front rotor speed so that to recover the relative wind. In addition, the results showed that having a pitch difference between the front and rear rotor of $3^{0}$ reflects in a higher DRWT performance. According to the investigation results, controlling the pitch angle side by side with optimizing the rotational speed has further effect in the increase of the performance of the CRWT to $4 \%$.

In 2007, (Shen, Zakkam, Sorensen, \& Appa, 2007) done an investigation targeting the CRWTs using actuator line technique. The paper recommended the CRWT over the CWT. The distance separating the two rotors was stated to be insignificant except at very close distance where the thrust coefficient will be noticeably fluctuating and accordingly the power will decrease. In addition, the paper indicated that the power coefficient of the front rotor is higher than that of rear one, after lowering the rotational speed around TSR of 3, the power coefficient of the two rotors reaches to nearly being the same value. Finally, it was stated that the DRWT has an expected annual increase in power extraction of $43.5 \%$ based on wind speed ranging from 5 to $25 \mathrm{~m} / \mathrm{s}$ distributed using Weibull distribution.

In 2010, (Lee , Kim, \& Lee, Analysis of aerodynamic characteristics on a counter-rotating wind turbine, 2010) compared the performance of two bladed and four bladed single turbine to two bladed CRWT. The numerical study was done using free wake vortex lattice method on $10 \mathrm{~m}$ diameter rotors operating at 72 $\mathrm{rpm}$. The effect of rotors solidity was taken into consideration, resulting in 5\% decrease in CRWT Cp when it is compared to four bladed single rotors that is of equal solidity due to the interaction between front and rear rotors. While in case the comparison is held with a two bladed turbine of half solidity, the performance was found to increase about $30 \%$.

(Herzog, Schaffarczyk, Wacinski, \& Zurcher, 2010), studied the performance of 0.8 diameter CRWT using experimental analysis in wind tunnel and CFD simulations. The study showed a power extracted from front rotor is $74 \%$ while for the rear rotor of only $26 \%$. The study resulted in a $9 \%$ increase in Cp compared to SRWT. Further numerical analysis was conducted by (Hoang \& Yang, 2014) on constant wind speed of 10 $\mathrm{m} / \mathrm{s}$ and variable TSR. The configuration studied having diameter of $7.16 \mathrm{~m}$ for front and rear rotors and spacing of $1 \mathrm{D}$. The peak of SRWT indicated was 37\% at TSR of 6, while that of CRWT was 39\% at TSR of 5. In addition, the paper recommended the operation of the DRWT at low TSR where it showed a noticeable advantage in the performance compared to SRWT.

In 2015, (Ozbay, Tian, \& Hu, 2015) has done the study experimentally in wind tunnel to investigate the characteristics of DRWTs. The rotational speed of the rotor turbines was adjusted using DC electricity generator to apply various electric loads to adapt the rpm that is equivalent to changing of TSR from 0 to 6.5. The power output of the SRWT, CWT and CRWTs were recorded and comparisons were conducted among them. The SRWT model has $140 \mathrm{~mm}$ radius and tower height of $225 \mathrm{~mm}$. Spacing between the two rotors are 0.25 rotor diameter and the wind speed $5 \mathrm{~m} / \mathrm{s}$. The experiment resulted in an increase of $48 \%$ in case of CWT and $60 \%$ in case of CRWT compared to SRWT.

From the literature review, it was observed the capability of the MRF technique in the CFD simulations to provide accurate results with less computational domain size. In addition, the previous work done whether it is using experimental or numerical methods, has showed the effect of varying each of the design parameters on the dual rotor wind turbines performance. Throughout the current study, MRF technique will be employed in optimizing the DRWT configuration and performance. The optimization will be conducted in 
respect to the change of three vital parameters, which are the axial spacing between the front and rear rotor, the pitch angle of the rear rotor and rotation speed ratio between the two rotors.

Current study performed using CFD software, which has governing equations linked to fluid dynamics (Tu, Yeoh, \& Liu, 2008). The equations of the fluid dynamics are the backbone for the CFD software. The current case study is having 3D Steady turbulent flow. For such flow, the main equations used in solving are the continuity equation, momentum equations in three Cartesian coordinates and the turbulent flow model equations (Sayma, 2009).

\section{Model Validation}

Referring to the experimental work done by (Krogstad \& Lund, An experimental and numerical study of the performance of a model turbine, 2012) on $0.9 \mathrm{~m} \mathrm{SRWT}$. The Wind turbine was experimentally investigated in National Renewable energy laboratory in Colorado. The Blade is having S826 airfoil. The model performance was investigated at upwind velocity of $10 \mathrm{~m} / \mathrm{s}$ and then further study was held with a numerical methodology using BEM theory and CFD. The study included the change of TSR with same upcoming wind speed shown in fig. (1). CFD model was done using MRF technique, K-w SST turbulence model, also stating that this model is best to detect the drag and lift coefficient $\mathrm{Cd}$ and $\mathrm{Cl}$ of wind turbines and that was also recommended in previous studies as that held by (Hansen, Sorensen, Voutsinas, Sorensen, \& Madsen, 2006) and by (Hsiao, Bai, \& Chong, 2013). Taking into consideration that the Y+ value to be lower than 5. The Domain of the study was 4.5 D (rotor diameter) upstream, 7.8 D downstream and domain radius of 6.7 D. The mesh used was of $3.5 \times 10^{6}$ cells. Momentum equations are of first order upwind scheme and first order pressure interpolation.

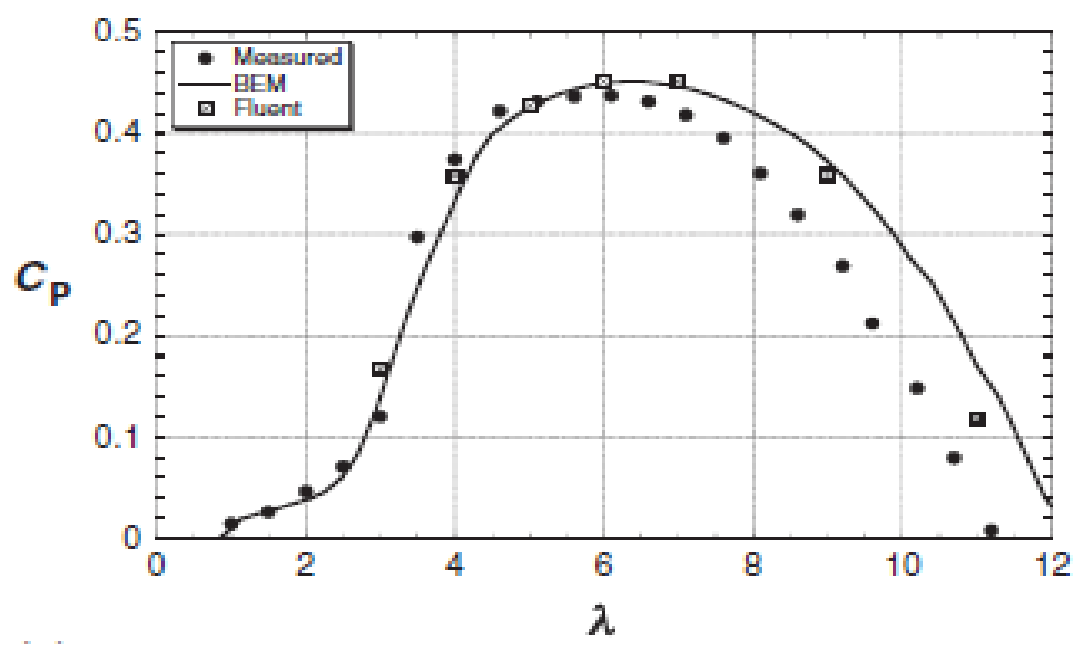

Figure 1: $C p$ vs TSR (Krogstad \& Lund, An experimental and numerical study of the performance of a model turbine, 2012)

In the present study, the model will be validated with the previous work by (Krogstad \& Lund, An experimental and numerical study of the performance of a model turbine, 2012). The study takes place computationally using CFD, MRF technique with K-w SST turbulence model as suggested earlier (Hsiao, Bai, \& Chong, 2013), (Krogstad \& Lund, An experimental and numerical study of the performance of a model turbine, 2012). Momentum equations of second order upwind scheme used. In order to validate the work, certain phases was done. Starting with the domain independent test, mesh independent test and ending up with the variation of the coefficient of performance versus with TSR.

\section{Domain Independent Test}

The MRF technique includes two domains, the stationary domain, which is the main domain, and the rotating one, which has the same rotational speed of the blade. Domain independent test is carried out on both domains.

\section{Main Domain independent test}


The coefficient of performance of the blade investigated with the change of the main domain size. Table (2) list down the different domains taken into consideration ending up with the domain size \#6 at which the $\mathrm{Cp}$ start to be not affected by the main domain size increase as shown in fig. (2).

Table 1: Main Domain sizes studied in the Main Domain independent Test

\begin{tabular}{|c|c|c|c|}
\hline$\#$ & Up stream $(\mathbf{R})$ & Down Stream $(\mathbf{R})$ & Domain Redius (R) \\
\hline 1 & 1 & 8 & 5 \\
\hline 2 & 2 & 8 & 6 \\
\hline 3 & 3 & 9 & 6 \\
\hline 4 & 3 & 9.5 & 5 \\
\hline 5 & 3.5 & 9.5 & 5 \\
\hline $\mathbf{6}$ & $\mathbf{3 . 5}$ & $\mathbf{9 . 5}$ & $\mathbf{6}$ \\
\hline 7 & 4 & 10 & 6 \\
\hline 8 & 5 & 11 & 7 \\
\hline 9 & 6 & 12 & 7 \\
\hline
\end{tabular}

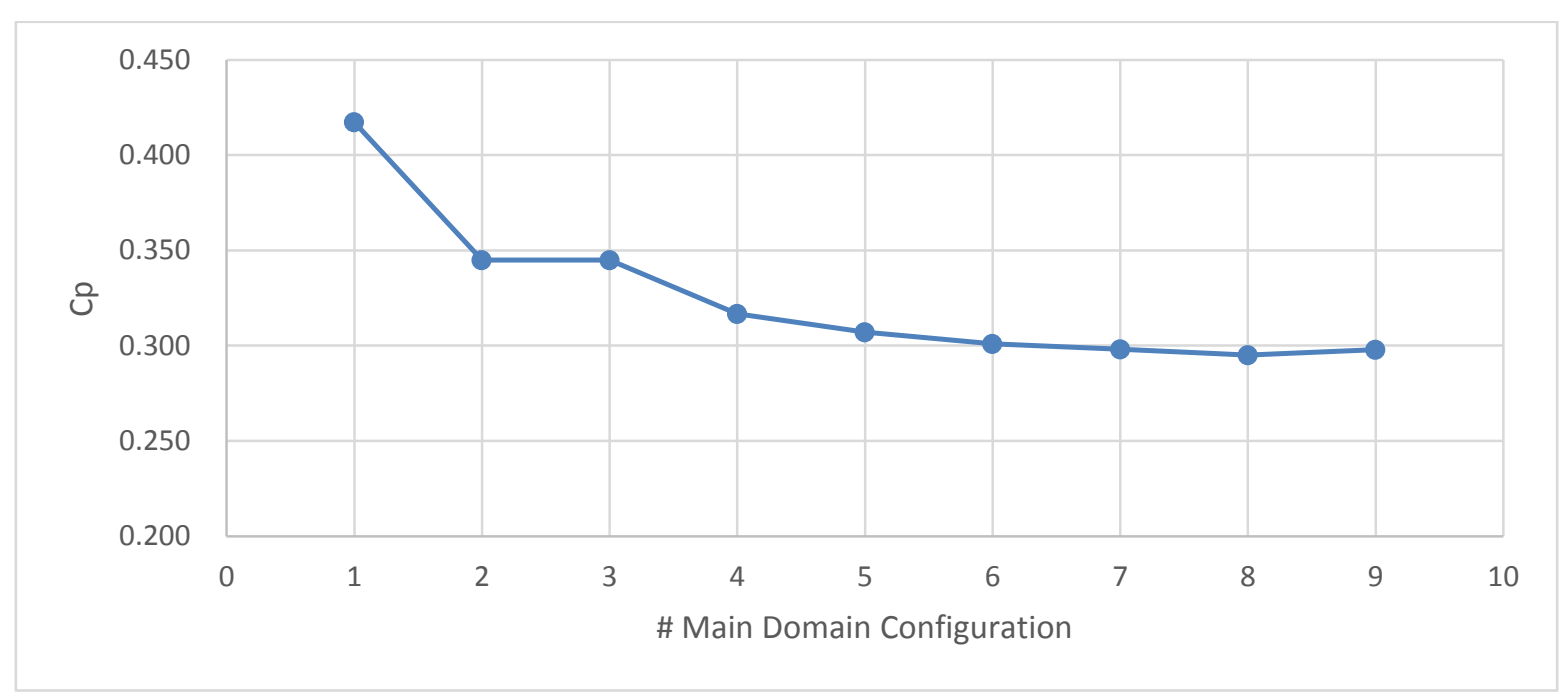

Figure 2: Change of Cp vs Main domain Configurations

\section{Rotating domain independent test}

A domain independent test for the rotating domain is carried out. The rotating domain size increase has no effect on the rotor performance beginning from rotating domain of $0.44 \mathrm{R}$ as an extrusion and $1.33 \mathrm{R}$ as a rotating domain radius

\section{Mesh Independent Test}

Mesh density has a major effect on the CFD simulation results. The Mesh variation effect on the blade is tested to ensure the independency of the simulation results. Y plus value is ensured to be below the value of 5 as recommended (Krogstad \& Lund, An experimental and numerical study of the performance of a model turbine, 2012). Ending up with mesh density with elements number of 3,007,342 and nodes number of 634,286 as shown in fig. (3). Fig.(4) shows a preview for the mesh focus on the rotating domain indicating the presence of the sphere of influence surrounding the blade. 


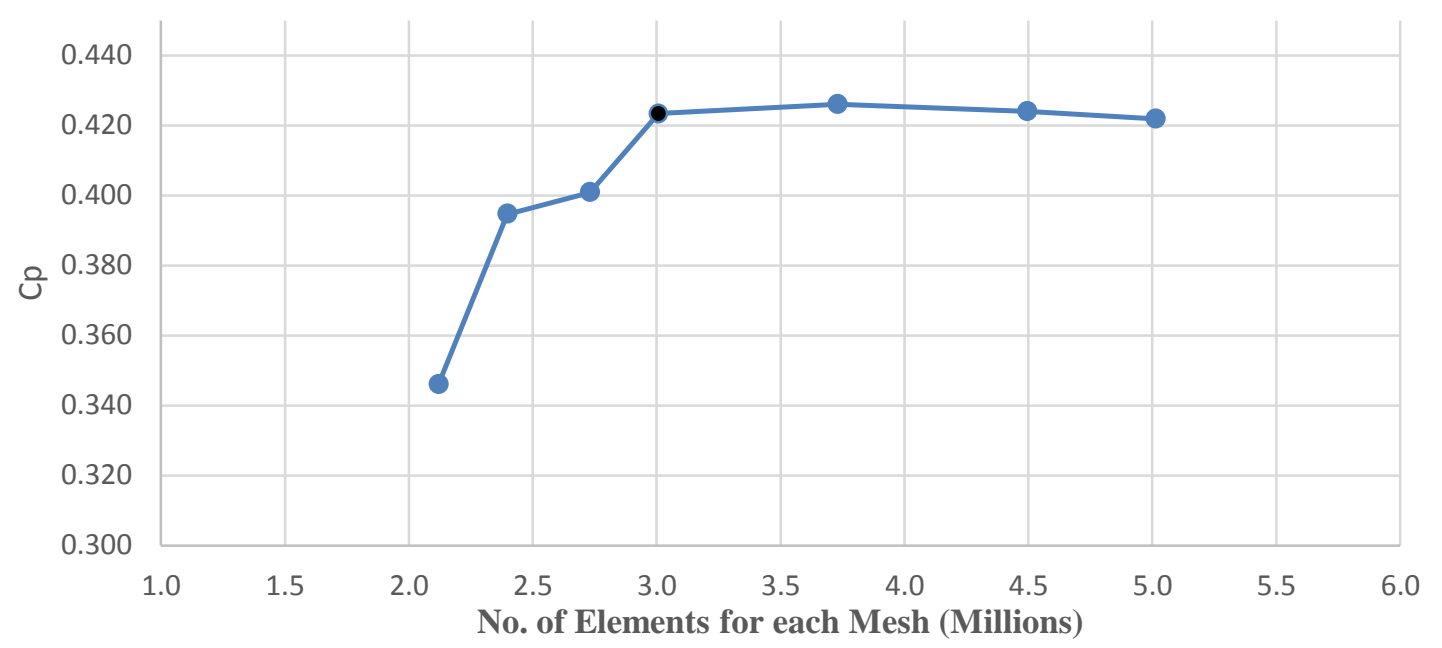

Figure 3: Change of $\mathrm{Cp}$ vs Mesh densit

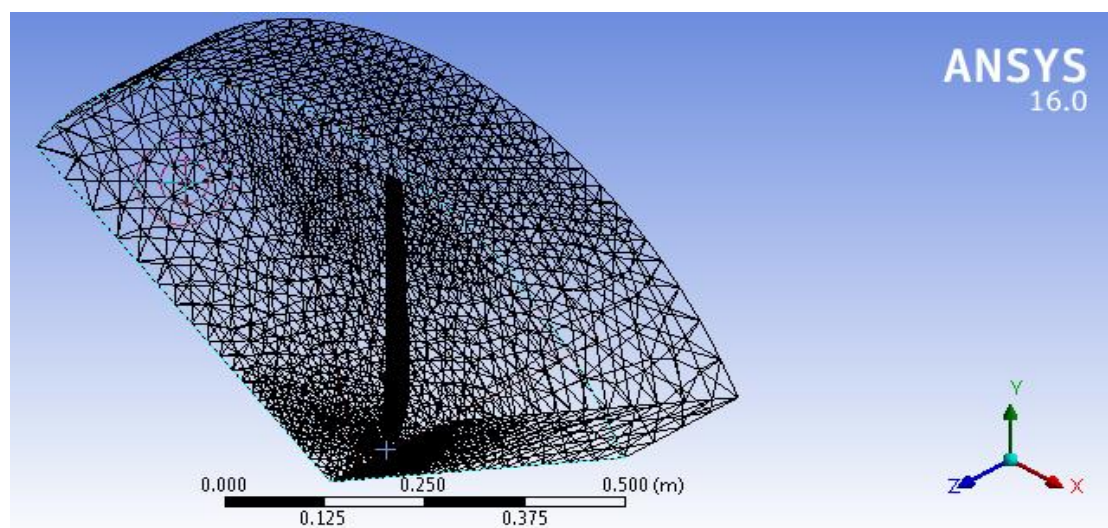

Figure 4: Mesh for the rotating domain with sphere of influence surrouding the blade

\section{Validation Results}

Finally, validating the CFD simulation results with previous work done (Krogstad \& Lund, An experimental and numerical study of the performance of a model turbine, 2012). Fig. (5) illustrates the variation of $\mathrm{Cp}$ with the TSR done in the present study and comparing it with the recorded work previously done experimentally and using CFD simulation. From the results presented, it is clear that the CFD simulation has the same trend same as the experimental and CFD work previously done, showing a small value of deviation that may be referred to the change in Y plus value within the range limit. The deviation is smallest at the peak Cp at TSR of 6, which confirms with the experimental and CFD work.

The previous work (Krogstad \& Lund, An experimental and numerical study of the performance of a model turbine, 2012) on S826 air foil stated that a stall effect will occur at TSR of 3 and 4, which is also indicated by the results presented in fig.(6) and (7). 


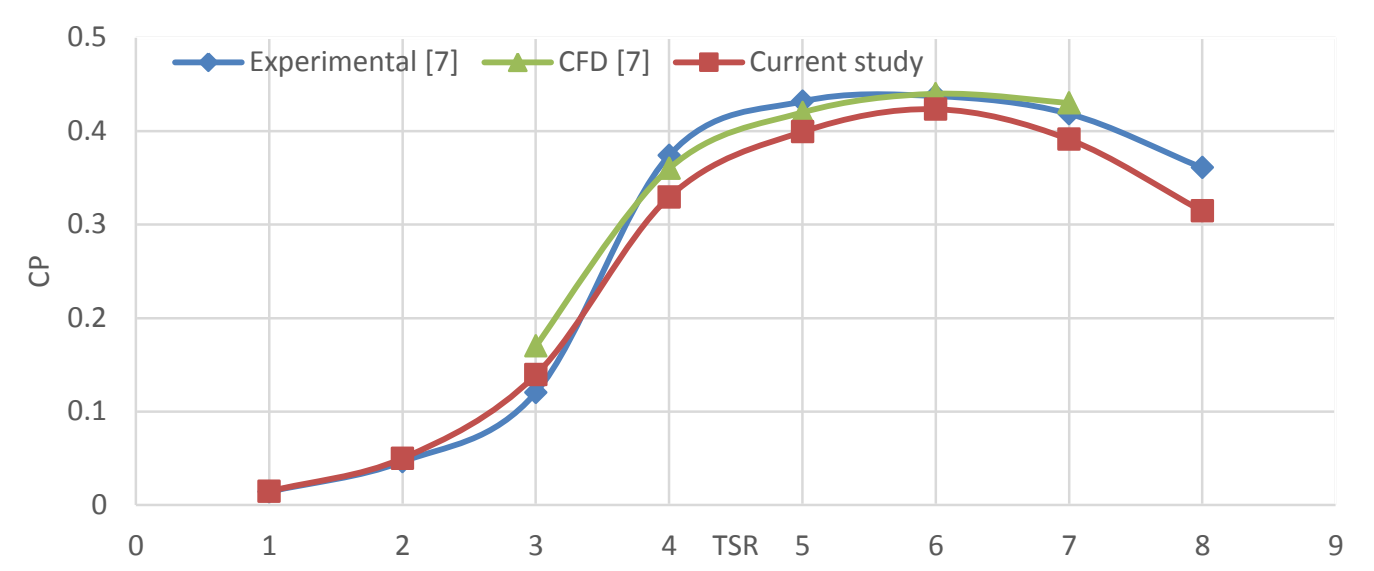

Figure 5: Comparison of Cp Vs TSR between previous work done experimentally and with CFD Vs present Study

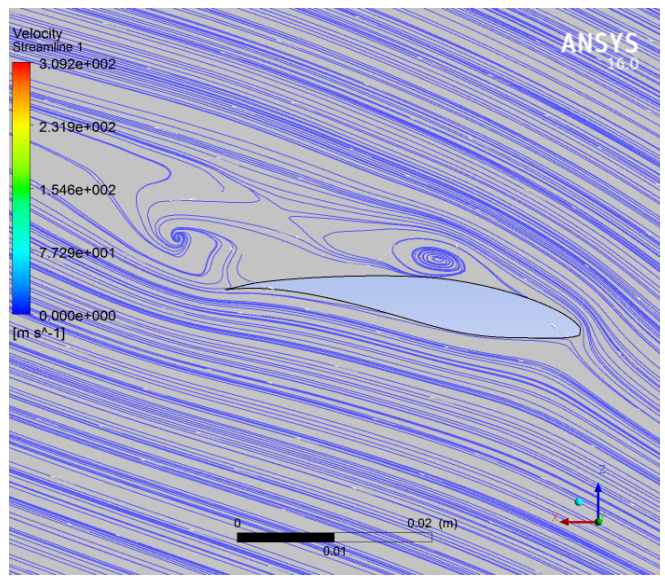

Figure 6: Streamlines representation $f$ or SRWT at TSR 3

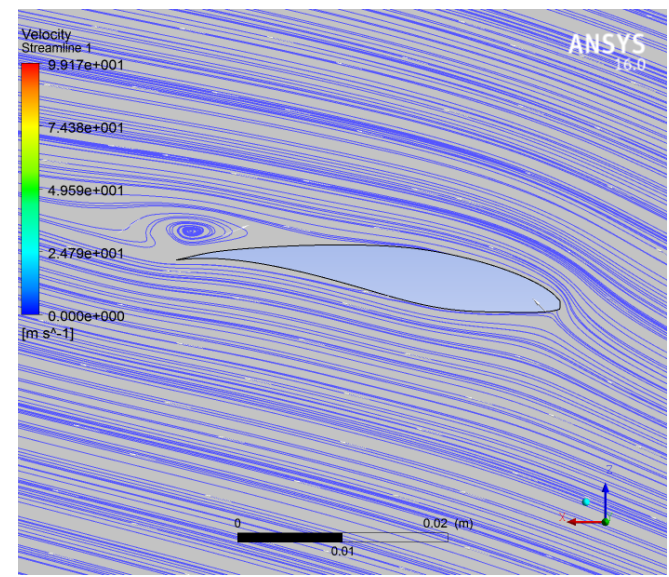

Figure 6: Streamlines representation for SRWT at TSR 4

\section{Results and Discussions}

CWT and CRWTs has the same idea in introducing a second rotor to the main rotor, rotating in the same direction or in opposing directions, this is previously studied in literature reviews indicating an expected increase in the overall rotor performance. The DRWT is far from having double the Cp of SRWT due to the effect of the interaction between the front and rear rotor. Second rotor has its effect in lowering down the performance of the front rotor due to the axial velocity decay after the front rotor (Jung, No, \& Ryu, 2005). In addition to that, turbulence occurrence cause a dramatic decrease in the performance of the rear rotor. The effect of axial distance separating the two rotors, the pitch angle of the rear rotor effect and the variation of rotational speed ratio between the two rotors are studied for both CWTs and CRWTs.

The DRWTs performance with different tip speed ratios are presented in fig. (8) and (9) at separating distance of $0.5 \mathrm{R}$ as recommended by early conducted study (Ozbay, Tian, \& Hu, 2015), pitch angle of $0^{\circ}$ for front and rear rotors and of rotational speed ratio of $1: 1$. While the diameter ratio is also kept to a ratio 1:1. Fig. (8) illustrates the performance of the CWT showing separately the performance of the front, rear and DRWT. Moreover, it compares these performances with the SRWT revealing certain conclusions to be taken into consideration. At low TSR, the front and rear performance are nearly equal and that agrees with previous study (Ozbay, Tian, \& Hu, 2015). At high TSR, the effect of the front rotor become dominant and the rear rotor effect is minimized until a TSR of 8 where the $\mathrm{Cp}$ of rear rotor is nearly ineffective. The peak performance of the CWT is at TSR of 5 with an increase of $12.8 \%$ from the peak of SRWT occurs at TSR of 6. The most significant remark regarding the performance of CWT is that it has a superior advantage over the SRWT at all TSR.

On the other hand, using the same configuration setup done in the CWT study, CRWT study was conducted. Fig. (9) shows the performance of the CRWT side by side with the SRWT. It shows also the effect of 
installing two counter rotating turbines on the front and rear rotors separately. The study reveals the following conclusions most significantly the increase of the peak performance of value $14 \%$ over the SRWT. The peak performance of the CRWT occurs at TSR of 4. In addition, same behavior of the CWT occurs for CRWT at low TSR, as the performance of the front and rear rotors became nearly the same and that of CRWT is nearly double Cp of that of the SRWT. The performance of the CRWT shows a high agreement to that stated in earlier study (Lee, Son, \& Lee, Velocity ingerference in the rear rotor of a counter rotating wind turbine, 2013). The overall conclusion is that the peak of the CRWT is higher compared to that of CWT. Moreover, the performance of CRWT at high TSR becomes lower to that of SRWT.

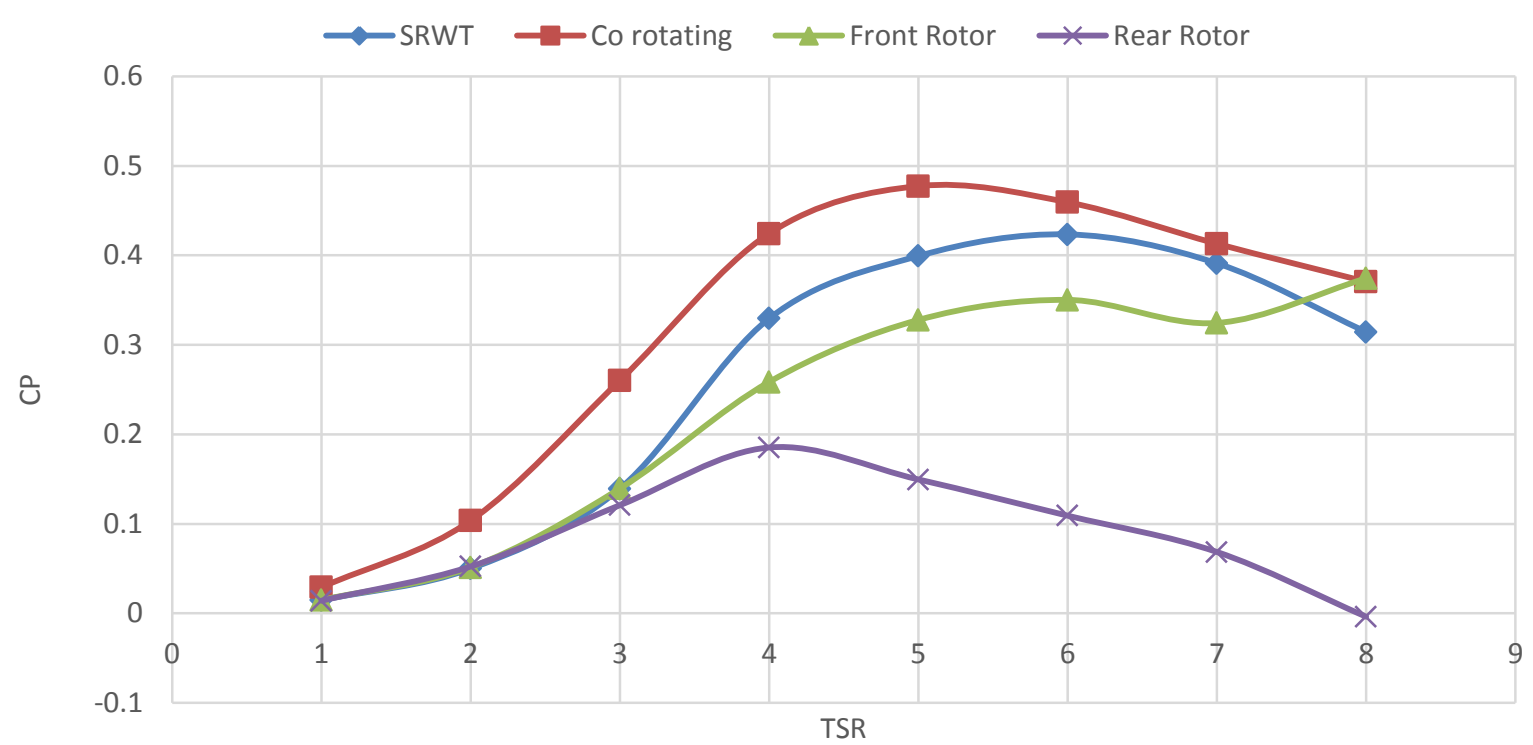

Figure 7: Comparisons for performances of the CWT, front, rear versus SRWT performance

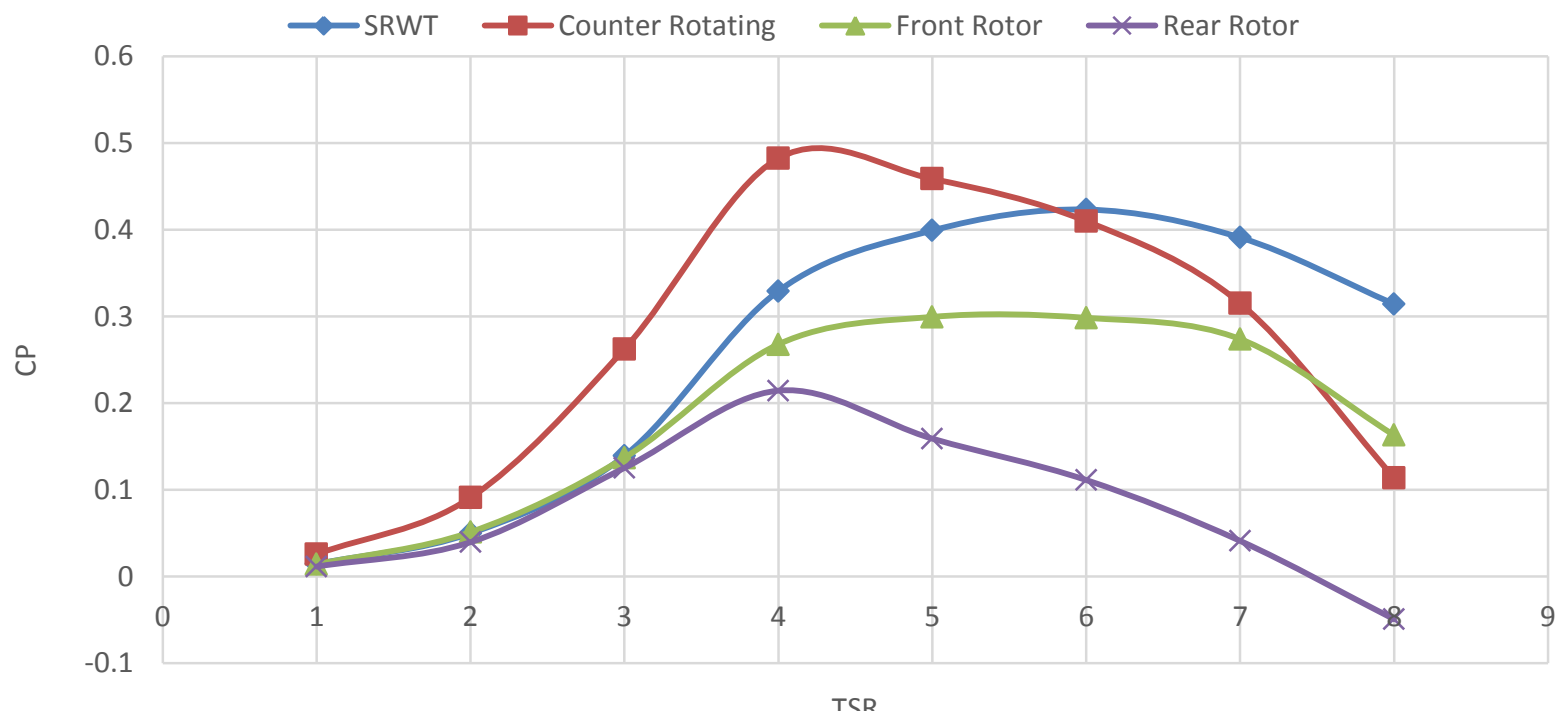

Figure 8:Comparisons for performances of the CRWT, front, rear versus SRWT performance

\section{Spacing between Rotors}

The axial spacing between the two rotors is a common factor to be studied to optimize the configuration and ensure better power coefficient output. As shown in fig. (10) and (11), the effect of changing the axial distance on the Co and counter rotating wind turbine at their peak TSR. Fig. (10) shows that the effect of the CWT at TSR of 5 which happens to be ineffective on the performance. That also agrees with previous study (Lee, Son, \& Lee, Velocity ingerference in the rear rotor of a counter rotating wind turbine, 2013). The performance of the front rotor increases with increasing the axial distance and vice versa, the performance of the rear rotor decreases, causing an overall no effect on the performance. That is due to decreasing the 
interaction between the two rotors resulting in higher performance for the front and lower performance for the rear rotor.

As for fig. (11) illustrating the spacing effect on the CRWT, showing same behavior to that of CWT except at very close spacing where there is fluctuation occurrence in the thrust coefficient referred to in previous study (Shen, Zakkam, Sorensen, \& Appa, 2007), which cause a decrease in the coefficient of performance at close spacing of $0.25 \mathrm{R}$. Fig. (12) and (13) shows the streamlines representation in case of having a close interaction between the CRWT rotors.

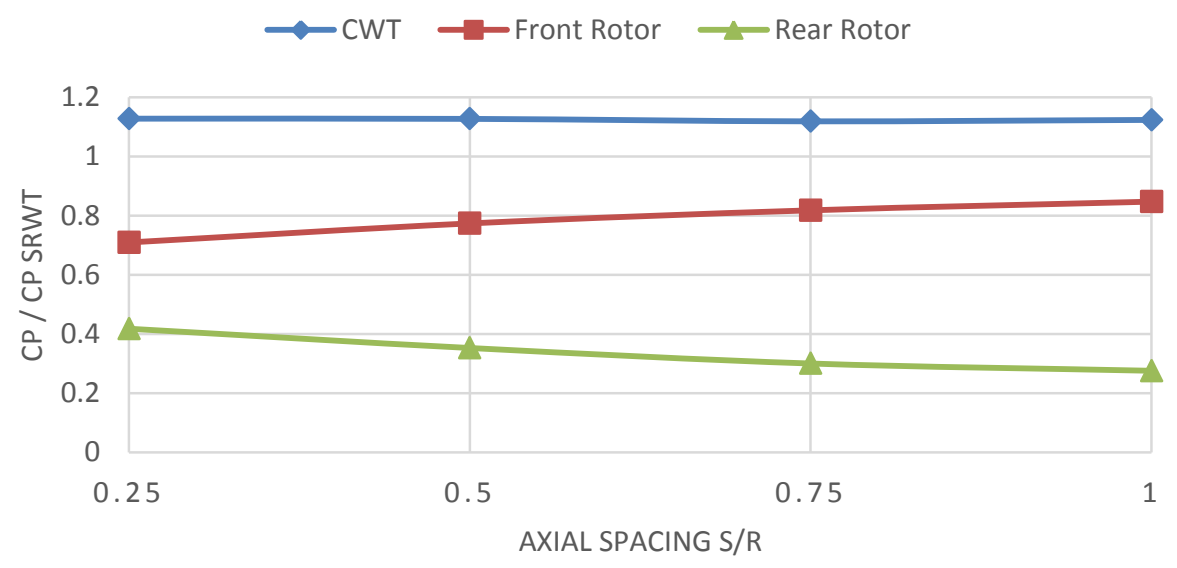

Figure 9: Coefficient of Performance change with axial distance at TSR 5 for front, rear and CWT versus SRWT at TSR 6

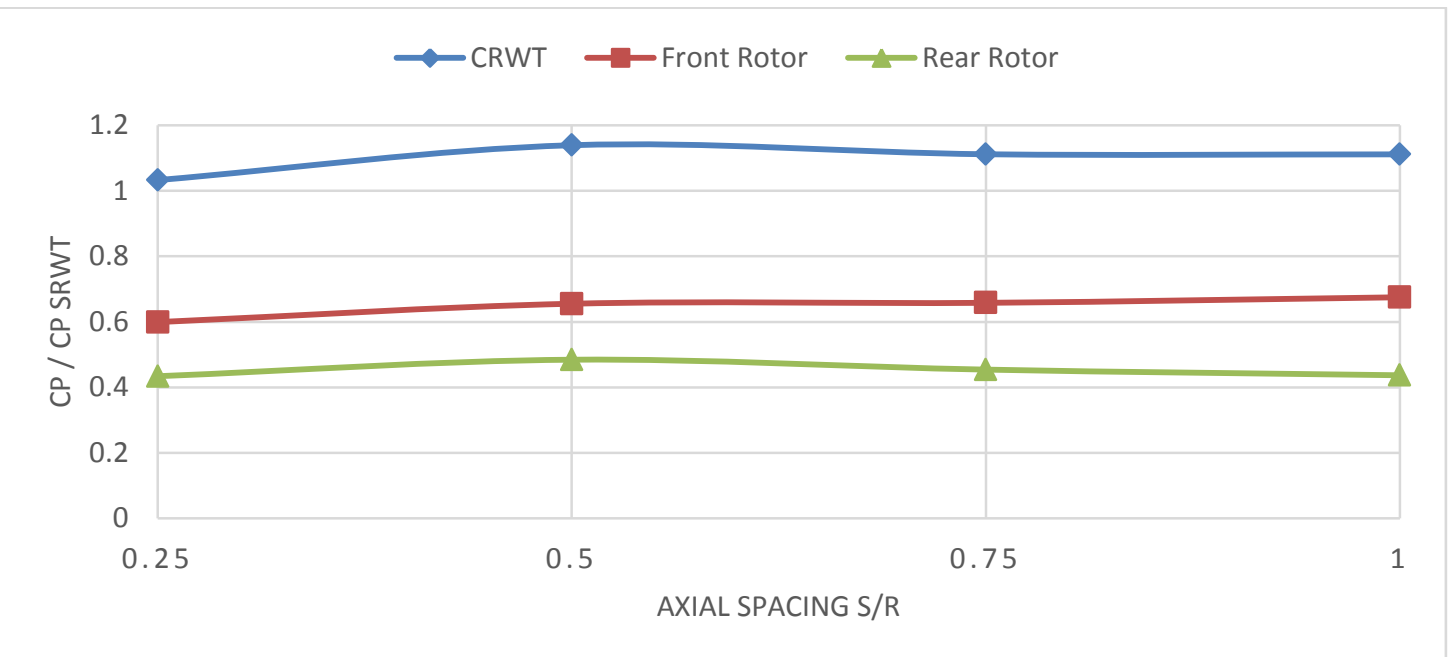

Figure 10:Coefficient of Performance change with axial distance at TSR 4 for front, rear and CRWT versus SRWT at TSR 6
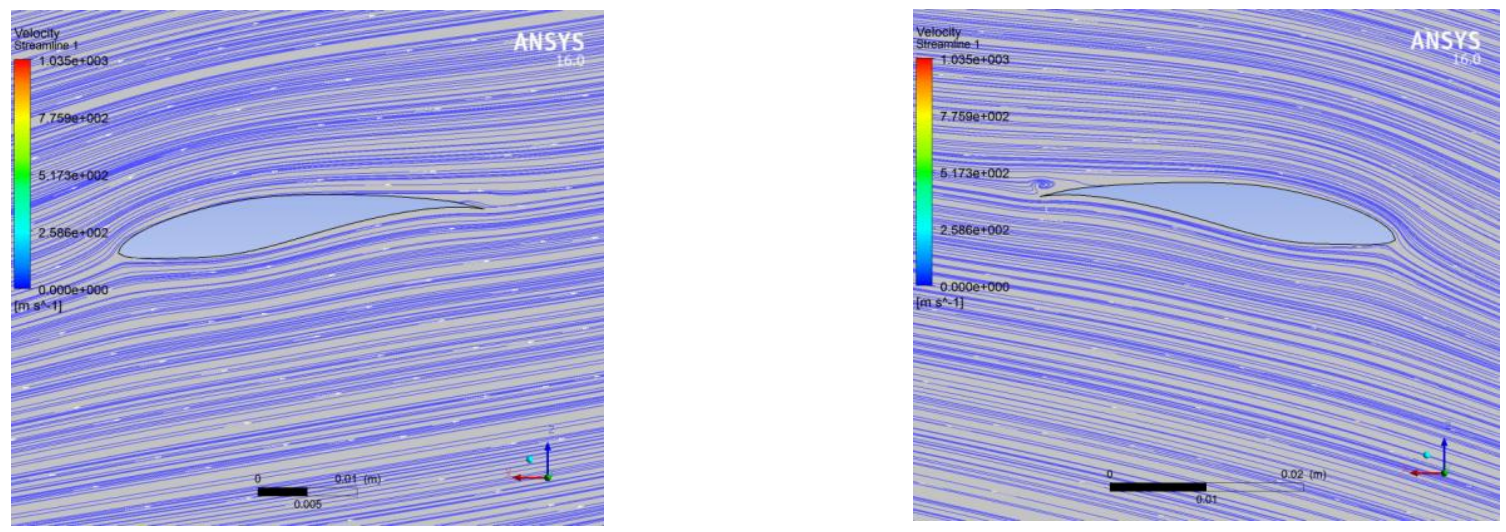
Figure 11: Streamlines representation for front rotor of CRWT at $0.25 R$ spacing
Figure 12: Streamlines representation for Rear rotor of CRWT at $0.25 R$ spacing

\section{Pitch Angle of Rear Rotor}

The effect of the pitch angle has been investigated in different studies as in (Lee, Kim, Son, \& Lee, 2012), (Krogstad \& Adaramola, Experimental investigation of wake effects on wind turbine performance, 2011), (Hansen, Sorensen, Voutsinas, Sorensen, \& Madsen, 2006) and (Priyono \& Saepudin, 2011) showing its effect on the DRWT performance. During this study, the pitch angle of the font rotor is fixed at $0^{0}$ and axial spacing of $0.5 \mathrm{R}$, while the effect of changing the pitch angle of the rear rotor is studied. The effect on the performance was presented in fig. (14) for the CWT and fig. (15) for the CRWT. In fig. (14), the change of the rear rotor pitch angle gives peak $\mathrm{Cp}$ at $0^{\circ}$. While at negative values, the overall $\mathrm{Cp}$ decreases. On the other hand, the pitch angle of positive values of $1^{0}$ and $2^{0}$ shows nearly no change compared to that at $0^{0}$. After wards, the performance is affected dramatically with further increase in the pitch angle.

On the Other hand, fig. (15) shows the effect of the rear rotor pitch angle variation on CRWTs performance. The effect of the pitch angle in CRWT happens to be same to that of the CWT. As the performance found to be also in effective when the blade is tilted up to $2^{0}$ towards the front rotor.

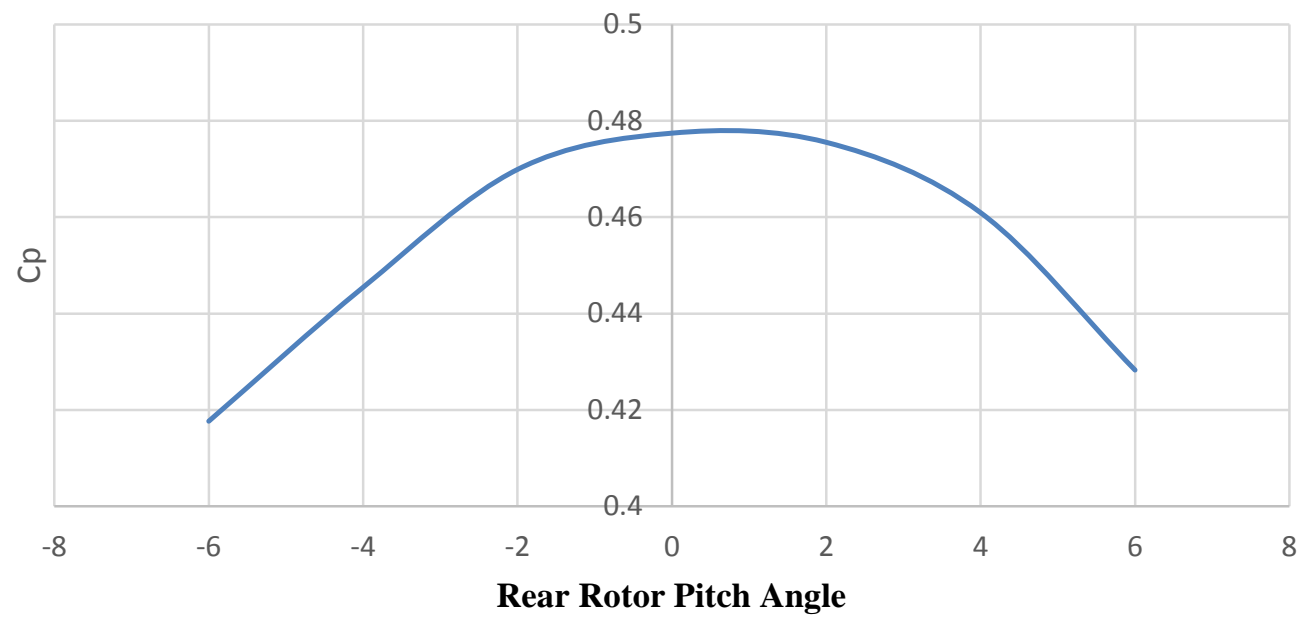

Figure 13: Performance of CWT with changing the rear rotor pitch angle at TSR 5

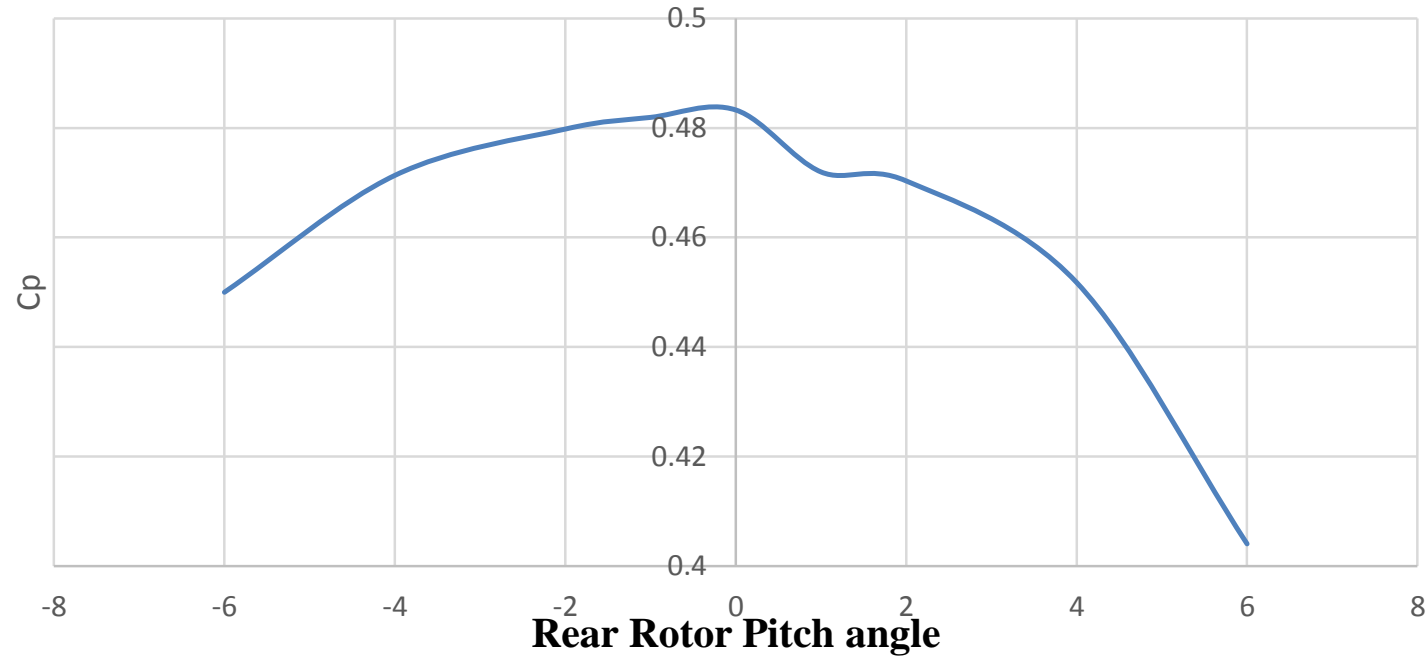

Figure 14: Performance of CRWT with changing the rear rotor pitch angle at TSR 4

In conclusion, both the Co and Counter rotating wind turbine are unaffected to the increase the interaction between front and rear rotors to a certain limit of $2^{\circ}$. Fig. (16),(17) and (18),(19) shows the streamline 
representation for CWT and CRWT in case of having rear rotor in both cases having pitch angle of $6^{0}$ at which the DRWT experienced a noticeable decrease in performance.

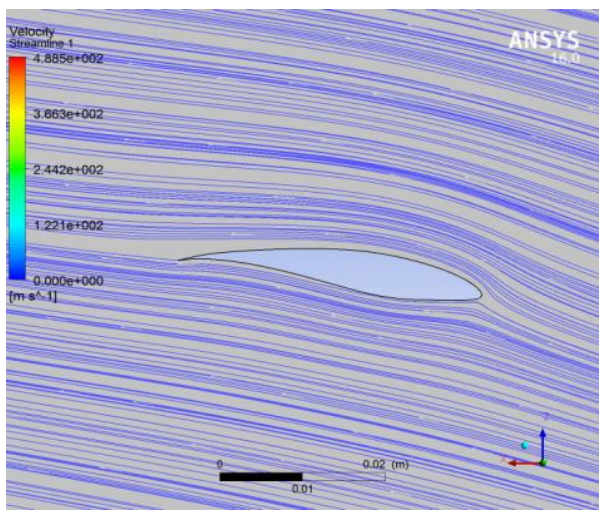

Figure 15:Streamlines for front rotor of CWT when rear rotor having pitch angle of 6

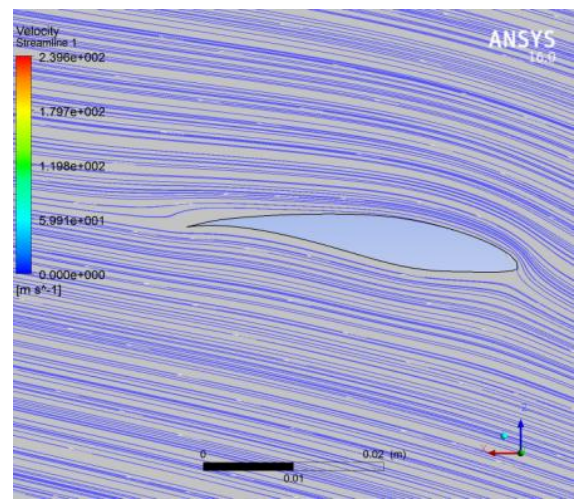

Figure 17: Streamlines for front rotor of CRWT when rear rotor having pitch angle of 6

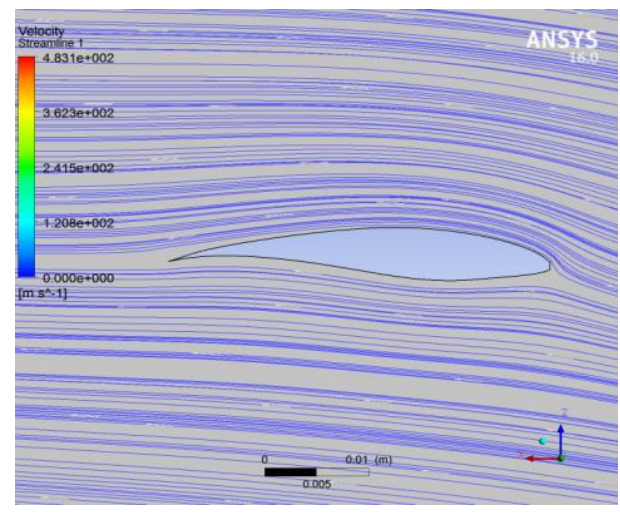

Figure 16: Streamlines for rear rotor of CWT when rear rotor having pitch angle of 6

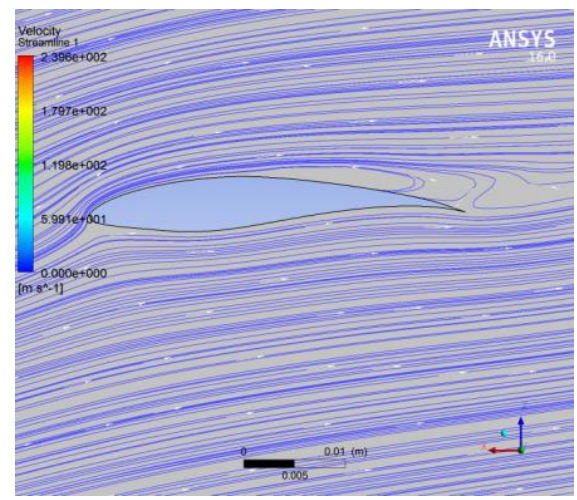

Figure 18:Streamlines for Rear rotor of CRWT when rear rotor having pitch angle of 6

\section{Rotational Speed Ratio Rear to Front Rotor}

The rotational speed ratio effect investigated in previously (Lee, Kim, Son, \& Lee, 2012), in which recommended to have the rotational speed of the rear rotor to be less than of the front rotor. In case of the rotational speed ratio of $1: 1$, the relative wind angle on the rear rotor is minimized. So that, decreasing the rotational speed of the rear rotor will recover the relative wind angle on the rear rotor. In other words, it will increase its performance. The study of the rotational speed ratio effect was conducted at axial spacing of 0.5 $\mathrm{R}$ and pitch angle of $0^{0}$ for front and rear rotors. The effect of the rotational speed ratio was investigated at TSR of 4, 5 and 6 for both Co-rotating and CRWTs.

Fig. (20) And (21) discuss the effect of the rotational speed ratio change on the performance of the Co and CRWTs. As shown in fig. (20), the rotational speed ratio effect at TSR 4 shows a better performance at ratios of 0.9 and 1 . As for TSR of 5, the speed ratio tends to have its peak value at speed ratio of 0.8 . Finally, for TSR of 6 , the peak $\mathrm{Cp}$ was found to be at speed ratio of 0.5. In summary, it is noticed that the performance at TSR 4 tends to be improved at high rotation speed ratios near to 1 . While at TSR 6 , the performance tends to increase to its peak at low speed ratios. As for TSR 5, it peak occurs at rotation speed ratio rear to front rotor between that of TSR 4 and 6 . In addition, the peak of the performance for the CWT found to be when the blade is operating at TSR of 5 with rotational speed ratio rear to front rotor is 0.8 .

In fig. (21), the behavior in Counter rotating configuration tends to be the same as that found for the Corotating. For TSR of 4 , the performance tends to be the better at high speed ratios. For TSR of 6 , the performance peak is at low speed ratios. While for TSR of 5, the performance peak is at rotation speed ratio 
of 0.8. It is noticeable to remark on the effect of changing the rotational speed has shifted the peak performance of CRWT from being at TSR of 4 to be peaked at TSR of 5 on operating at rotational speed ratio of 0.8 rear to front rotor. Also, noticed that the peak of each TSR for Counter and CWT occurs at the same rotation speed. In conclusion, the performance for CWTs improved by $2.7 \%$ compared to case of having speed ratio of $1: 1$. In case of CRWT, the improvement has reached to $5.5 \%$. In summary, the rotational speed effect on both Co and CRWTs need to taken into consideration in the design, taking into account that the parameter change shows a higher effect in case of the CRWTs.

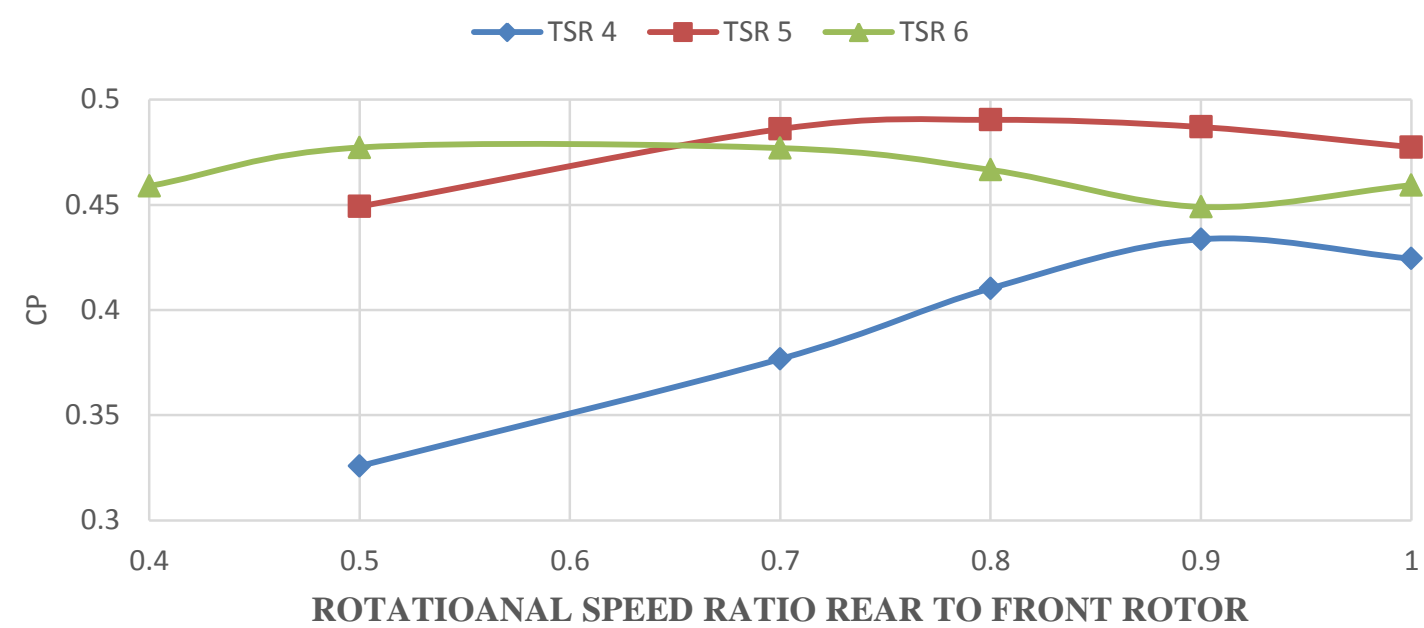

Figure 19: Cp vs rotation speed ratio rear to front rotor at TSR 4, 5 and 6 for CWT

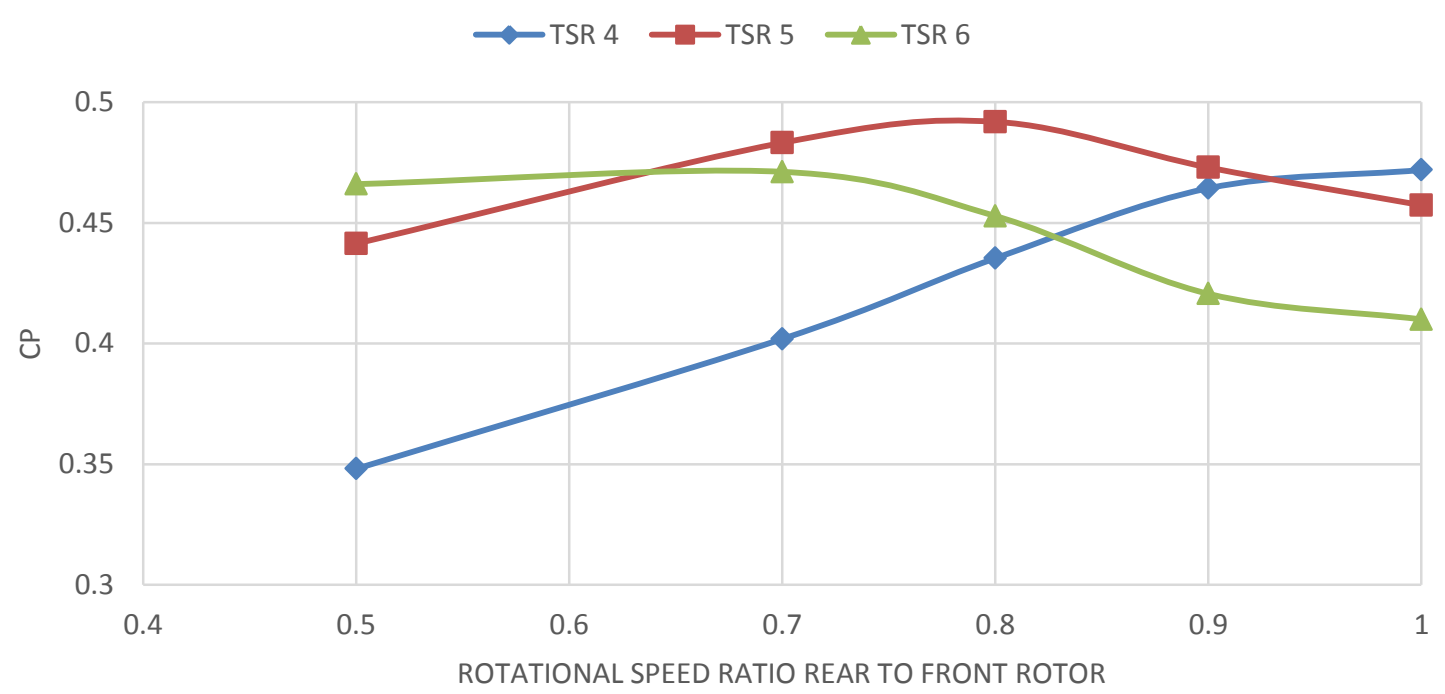

Figure 20:Cp vs rotation speed ratio rear to front rotor at TSR 4, 5 and 6 for CRWT

\section{Conclusion}

It is worth saying that the Co and Counter rotating configurations have both their strong and weak points. It is always based on the application and the available parameters to control in the design stage. Throughout the study, the effect of axial spacing, pitch angle of the rear rotor and the rotation speed ratio rear to front rotor studied on both the Co and Counter rotating wind turbine configurations.

For the CWT, the following is concluded

- Effect of axial distance separating the turbines on the performance is negligible.

- The Performance is always exceeding the SRWT performance at different TSR.

- The Performance increase is remarkable compared to SRWT at low TSR.

- Best orientation for the rear rotor to be at pitch angles $0^{0}, 1^{0}$ and $2^{0}$. In case that the front rotor pitch angle is fixed to $0^{0}$. 
- Rotation speed ratio of rear to front rotor gives best reflection on the performance at ratio of 0.8 when TSR is 5, with an increase of $2.7 \%$ compared to CWT at rotation speed ratio of 1:1 and an increase of $15.8 \%$ when compared to the SRWT peak performance.

As for the CRWT, the following is also concluded

- Effect of the axial distance was found to be negligible except at very close orientation where the performance is slightly affected by a decrease

- The Performance is exceeding the SRWT performance till TSR of 6, afterwards the SRWT Cp take the lead.

- The performance is also noticed to be promising at low TSR.

- Best orientation for the rear rotor when its pitch angle is $0^{0},-1^{0}$ and $-2^{0}$. In case that the front rotor pitch angle is fixed to $0^{0}$.

- Rotation speed ratio of rear to front rotor gives peak performance for the CRWT at TSR 5 when operating at rotation speed ratio of 0.8 . That will cause a further increase to the peak performance of the CRWT by $5.5 \%$ and of $20 \%$ compared to SRWT peak performance.

\section{Bibliography}

[1.] National Institute of Statistics. (2019, July). National Accounts from 2018. National, p. pp19.

[2.] Abdelrahman, M., Abdellatif, O., Moawed, M., Eliwa, A., \& Misak, S. (2015). The CFD Performance Analysis for Hoziontal Axis wind Turbine with Different Blade Shapes and Tower Effect. IEEE.

[3.] Ajzen., I. (2002). Perceived Behavior Control, Self-Efficacy, Locus of Control, and the Theory of Planned Behavior. Journal of Applied Social Psychology, pp. 665-683.

[4.] Appa, K. (2002). Energy Innovations Small Grant (EISG) program (Counter Rotating Wind Turbine System). California, US.

[5.] Augustine, J. T. (2016). Shapero's Model: A Veritable Tool for Explaining EntrepreneurialIntentions and Attitudes among Management Technology. International Journal of Business and Management Invention, pp 19-26.

[6.] Azjen, I. (1991). The Theory of Planned Behavior. Massachusetts: Elsevier.

[7.] Azjen., I. (1987). Attitudes, Traits and Actions: Dispositional Prediction of Behavior in Personality and Social Psychology. Advances in Ex-perimental Social Psychology. Amherst: Academic Press.

[8.] Azjen., I. (1987). Attitudes, Traits and Actions: Dispositional Prediction of Behavior in Personality and Social Psychology. Advances in Ex-perimental Social Psychology. 1-63.

[9.] Bandura, A., \& Wood, R. (1989). Effect of Perceived Controllability and Performance Standards on Self-Regulation of Complex Decision Making. Journal of Personality and Social Psychology, Vol. 56, No. 5, 805-814.

[10.] Bandura., C. A. (1986). Differential Engagement of Self-reactive influences in cognitive motivation. Organizational Behavior and Human Decision Processes.

[11.] Berglund, H. (2005). Between Cognition and Discourse: Phenomenology and the Study of Entrepreneurship. International Journal of Entrepreneurial Behaviour \& Research., 472-288.

[12.] Bhide, A. (2000). The Origin and Evolution of New Business. New York: Oxford Press.

[13.] Bhide, A. (2000). The Origin and Evolution of New Businesses. Oxford: Oxford University Press.

[14.] Bird, B. (1988). Implementing Entrepreneurial Ideas: The Case for Intentions. Illinois: Acad Manage Review.

[15.] Bonett, Douglas \& A. Wright, Thomas. (2014). Cronbach's alpha reliability: Interval estimation, hypothesis testing, and sample size planning. Journal of Organizational Behavior. 
[16.] Boyd, N. G., \& Vozikis, G. S. (1994). The Influence of Self-Efficacy on the Development of Entrepreneurial Intentions and Actions. Sage Journals.

[17.] Burneyl, Saleem, \& Hussain. (2008). Inductive and Deductive Research Approach.

[18.] Cantharasenawong, C., Suwantragul, B., \& Ruangwiset, A. (2008). Axial Momentum Theory for turbines with Co-axial Counter Rotating Rotors. Commemorative International Conference. Bangkok.

[19.] Chan, S. F.-S. (2000). The Role of Perceived Behavioral Control in Predicting Human Behavior: A Meta-Analytic Review of Studies on the Theory of Planned Behaviour. Hong Kong: Chinese University of Hong Kong.

[20.] Chiou, Y.-F. (2011). Perceived Usefulness, Perceive Ease of Use, Computer Attitude, and Using Experience ofWeb 2.0 Applications as Predictors of Intent to Use Web 2.0 by Pre-service Teachers forTeaching. Middleton: Yu-Fang Chiou.

[21.] Cooke, P. R. (2004). Moderation of Cognition-intention and Cognition-behavior relations: A Metaanalysis of Properties of Variables from the Theory of Planned Behavior. British Journal of Social Psychology, 159-186.

[22.] Council, G. W. (2015). Global Wind report.

[23.] Crant, M. J. (1996). The Proactive Personality Scale as a Predictor of Entrepreneurial Intentions. Journal of Small Business Management, pp42-49.

[24.] Crick, C. C. (1998). Does Entrepreneurial Self-efficacy distinguish Entrepreneurs from Managers? Journal of Business Venturing, 295-316.

[25.] Dahl, M. S., Praag, M. v., \& Thompson, P. (2014, May). Entrepreneurial Couples. IZA, p. 30.

[26.] Davidsson, P. (1995). Determinants of Entrepreneurial Intentions. RENT IX Worshop, (pp. 23-24). Jönköping.

[27.] Debleser, Y., \& Jermont Industrie. (2003). Patent No. 6504260. US.

[28.] Fielden, S. a. (2004). "Entrepreneurship and social inclusion". Emerald Group Publishing Limited.

[29.] Frese, M. (2009). Toward a Psychology of Entrepreneurship -An Action Theory Perspective. Foundations and Trends in Entrepreneurship, pp 437-496.

[30.] Garson, G. D. (2012). Testing Statistical Assumptions. Statistical Publishing Associates.

[31.] Gustafsson, V. (2006). Entrepreneurial Decision-Making; Individual Tasks \& Cognitions. Northhampton: Edward Elgar Publishing Limited, Inc.

[32.] Hansen, M., Sorensen, J., Voutsinas, S., Sorensen, N., \& Madsen, H. (2006). State of the art in wind turbine aerodynamics and aeroelasticity. Science Direct, 42, 285-330.

[33.] Herzog, R., Schaffarczyk, A., Wacinski, A., \& Zurcher, O. (2010). Performance and stability of a counter-rotating windmill using a planetary gearing: Measurments and Simulation. European Wind Energy Conference EWEC. Warsaw.

[34.] Hoang, A. D., \& Yang, C. J. (2014). Design and Performance Evaluation of a 10kW Scale Counter Rotating Wind Turbine Rotor. Journal of the Korean Society of Marine Environment \& Safety, 20, 104-112.

[35.] Hsiao, F.-b., Bai, C.-J., \& Chong, W.-T. (2013). The performance test of three different horizontal axis wind turbines (HAWT) blade shapes using experimental and numerical methods. Energies, 6 , 2784-2803.

[36.] Huang, L. (2018). Exploring the Strengths and Limits of Strong andWeak Sustainability Indicators: A Case Study of the Assessment of China's Megacities with EF and GPI. Sustainability, pp14. 
[37.] Hwang, B., Lee, S., \& Lee, S. (2013). Optimization of a counter-rotating wind turbine using the blade element and momentum theory. Journal of Renewable and Sustainable Energy, 5.

[38.] Joop, H., \& Timo, B. (1999). An Introduction to Structural Equation Modeling. Family Science Review.

[39.] Jung, S., No, T.-S., \& Ryu, K.-W. (2005). Aerodynamic performance prediction of a $30 \mathrm{kw}$ Counter-rotating wind turbine system. Renewable Energy, 30, 631-644.

[40.] Kamonthip, S. P.-C. (2016). Application of the Extended Theory of Planned Behavior Model to Investigate Purchase Intention of Green Products among Thai Consumers. Sustainability Open Acess Journals.

[41.] Kanemotor, T., \& Galal, A. (2006). Development of Intelligent Wind Turbine Generator with Tandem wind rotors and double rotational Armatures. JSME International Journal Series B Fluids and Thermal Engineering, 49(2), 450-457.

[42.] Kathleen, G. K. (2017). Shifting Curricular Approaches to Learning Beyond The Classroom. Sage Journals, pp. 22-31.

[43.] Khan, T., \& Mubashera. (2012). Axiology.

[44.] Kirzner, I. (1973). Competiotion \& Entrepreneurship. Chicago: University of Chicago Press.

[45.] Knight, H. F. (1921). Risk, Uncertainty and Profit. Washington, DC: Beard Books.

[46.] Krogstad, P., \& Adaramola, M. (2011). Experimental investigation of wake effects on wind turbine performance. Renewable Energy, 36, 2078-2086.

[47.] Krogstad, P., \& Lund, J. (2012). An experimental and numerical study of the performance of a model turbine. Wind Energy, 443-457.

[48.] Krueger. (1993). The Impact of Prior Entrepreneurial Exposure on Perceptions of New Venture Feasibility and Desirability”,. Entrepreneurship Theory and Practice, Vol. 18 No. 1, pp. 5-21.

[49.] Krueger, N. J., \& Reilly, M. D. (2000). Competing models of entrepreneurial Competing models of entrepreneurial. Journal of Business Venturing, Vol. 15, pp. 411-32.

[50.] Krueger, N., \& Carsrud, A. (1999). Entrepreneurial intentions:Applying the theory of planned behaviour. Bozeman: Taybr \& Francia Ltd.

[51.] Kumar, P., Bensingh, R., \& Abraham, A. (2012). Computational Analysis of $30 \mathrm{Kw}$ Contra Rotor Wind turbine. ISRN Renewable Energy.

[52.] LaMorte, W. (2019, September 20 Friday). The Theory of Planned Behavior. Retrieved from Behavioural Change Models: http://sphweb.bumc.bu.edu/otlt/MPHModules/SB/BehavioralChangeTheories/

[53.] Lee, S., Kim, H., \& Lee, S. (2010). Analysis of aerodynamic characteristics on a counter-rotating wind turbine. Current Applied Physics, 10, 339-342.

[54.] Lee, S., Kim, H., Son, E., \& Lee, S. (2012). Effects of design parameters on aerodynamic performance of a counter rotating wind turbine. Renewable Energy, 42, 140-144.

[55.] Lee, S., Son, E., \& Lee, S. (2013). Velocity ingerference in the rear rotor of a counter rotating wind turbine. Renewable Energy, 54, 235-240.

[56.] Marija, M. J. (2015). The role of subjective norms in forming the intention to purchase green food. Economic Research, 738-748.

[57.] McClelland, D. (1961). The Achieving Society. Illinois: Princeton.

[58.] McClelland, D. (1961). The Achieving Society. New York: Van No Strand. 
[59.] McMullen, J. (2006). Entrepreneurial Action and the Role of Uncertainty. Academy of Managerial Review, pp 22.

[60.] Mitulet, L. A., Oprina, G., Chihaia, R. A., Nicolaie, S., Nedelcu, A., \& Popescu, M. (2015). Wind Tunnel Testing for a New Experimental Model of Counter-Rotating Wind Turbine. Science Direct, $100,1141-1149$.

[61.] Mogey, N. (2007).

"So You Want to Use a Likert Scale?" Learning Technology Dissemination Initiative. http://www.icbl.hw.ac.uk/ltdi/cookbook/info_likert_scale/index.html.

[62.] Nee, A. A. (2012). Determinants of behavioural intention on sustainable food consumption among consumers of low income group: Empirical evidence from Malaysia. WEI International Academic European Conference, (pp. pp84-93). Zagreb.

[63.] Newman , B. (1986). Multiple Actuator - Disc Theory for wind turbines. journal of wind engineering and industrial aerodynamics, 24, 215-225.

[64.] Newman, B. (1983). Actuator Disc Theory for Vertical Axis Wind Turbines. Journal of Wind Engineering and Industrial Aerodynamics, 15, 347-355.

[65.] Oprina, G., Chihaia, R., El-Leathey, L., Nicolaie, S., Babutanu, C., \& Voina , A. (2016). A Review on Counter Rotating Wind Turbines. Journal of Sustainable Energy, 7.

[66.] Ozbay, A., Tian, W., \& Hu, H. (2015). An Experimental investigation on the wake characteristics and aeromechanics of Dual-rotor wind turbines. Proceedings of ASME Turbo Expo. Montreal.

[67.] Priyono, S., \& Saepudin, D. (2011). Design and Blade Optimization of Contra Rotation Double Rotor Wind turbine. International Journal of Mechanical \& Mechatronics Engineerin, 11(1).

[68.] Prudon, P. (2013). Confirmatory factor analysis: a brief introduction and critique.

[69.] Robert, B. (2006). Opportunity Recognition as Pattern Recognition: How Entrepreneurs "Connect the the Dots" to Identify New Business Opportunities. Academy of of Management Perspectives, 104-119.

[70.] Santos, R. d. (2014, January 20). EFFECTUATION - THE BEST THEORY OF ENTREPRENEURSHIP YOU ACTUALLY FOLLOW, WHETHER YOU'VE HEARD OF IT OR NOT. Retrieved from NECROPHONE: https://necrophone.com/2014/01/20/effectuation-the-besttheory-of-entrepreneurship-you-actually-follow-whether-youve-heard-of-it-or-not/

[71.] Sarasvathy, S. D. (2001). What Makes Entrepreneurs Entrepreneurial? Daden Business Publishing, 9.

[72.] Sayma, A. (2009). Computational fluid dynamics. Sayma and Ventus .

[73.] Schumpeter, J. (1965). Economic Theory and Entrepreneurial History. In: Aitken HG (ed) Explorations in. Cambridge, MA: Harvard University Press,.

[74.] Shane, S. (2000). Prior knowledge and the Discovery of Entrepreneurial Opportunities,Organization Science. Academy of Management Review.

[75.] Shapero, A. (1975). The Displaced, uncomfortable Entrepreneur. Psychology Today.

[76.] Shen, W., Zakkam, V., Sorensen, J., \& Appa, K. (2007). Analysis of Counter Rotating Wind turbines. Journal of Physics, 75.

[77.] Sokol, A. S. (1982). The Social Dimensions of Entrepreneurship. Encyclopedia of Entrepreneurship, 72-90.

[78.] Solomon, D. M. (2018). INFLUENCE OF FINANCIAL RISK MANAGEMENT ON EMPOWERMENT OFWOMEN IN NAKURU EAST SUB-COUNTY. Journal of Business Management and Economic Review, pp 16. 
[79.] Sommer, L. a. (2011). Intention as a Cognitive Antecedent to International Entrepreneurship: Understanding the Moderating Roles of Knowledge and Experience. International Entrepreneurship Management Journal, pp111-142.

[80.] Stephen, F., Urbano, D., \& Hemmen, S. (2005). The Impact of Institutions on Entrepreneurial Activity: Managerial Decision Economics.

[81.] Strauss, Milton \& T Smith, Gregory. (2009). Construct Validity: Advances in Theory and Methodology. Annual review of clinical psychology.

[82.] Tang, K. L. (2012). Entrepreneurial alertness in the pursuit of new opportunities. Journal of Business Venturing, pp 7-94.

[83.] Tongco, M. D. (2007). Purposive Sampling as a Tool for Informant Selection. A Journal of Plats, People and Applied Research.

[84.] Tu, Yeoh, \& Liu. (2008). Computational Fluid Dynamics. Elsevier Inc.

[85.] Verbeke, V. I. (2006). Sustainable food consumption: Exploring the consumer attitude-behavioural intention gap. Journal of Agricultural \& Environmental Ethics, 19, 1-14.

[86.] Williams, B., Brown, T., \& Onsman, A. (2010). Exploratory factor analysis: A five-step guide for novices. Australasian Journal of Paramedicine.

[87.] Wiseman-Orr, M. L. (2006). Validation of a structured questionnaire as an instrument to measure chronic pain in dogs on the basis of effects on health-related quality of life.

[88.] Wood, R. (1989). Effect of Perceived Controllability and Performance Standardson SelfRegulation of Complex Decision Making. Journal of Personality \& Social Psychology, pp 805814.

[89.] Xie, C. (2014). Why Do Some People Choose to Become Entrepreneurs? An Integrative Approach. Journal of Management Policy \& Practice vol. 15(1) 2014, 14pp.

[90.] YUAN, W., Tian, W., Ozbay, A., \& Hu, H. (2014). An Experimental study on the effects of relative rotation direction on the wake interferences among tandem wind turbines. Science China, 57, 935-949. 